\title{
Configurações
}

Revista de sociologia

\section{O pós-colonial entre Norte e Sul: formulações teóricas, implicações políticas na batalha pela 'arma da teoria'}

Postcolonial between North and South: Theoretical formulations, political implications in the battle for the "weapon of theory"

Postcolonialisme entre Nord et Sud: formulations théoriques, implications politiques dans la bataille grâce à «l'arme de la théorie»

\section{Emanuelle Santos}

\section{OpenEdition}

\section{Edição electrónica}

URL: http://journals.openedition.org/configuracoes/2077

DOI: 10.4000/configuracoes. 2077

ISSN: 2182-7419

\section{Editora}

Centro de Investigação em Ciências Sociais

Edição impressa

Data de publição: 1 Dezembro 2013

Paginação: 141-153

ISBN: 1646-5075

ISSN: 1646-5075

\section{Refêrencia eletrónica}

Emanuelle Santos, «O pós-colonial entre Norte e Sul: formulações teóricas, implicações políticas na batalha pela 'arma da teoria' », Configurações [Online], 12 | 2013, posto online no dia 11 novembro 2014, consultado o 01 maio 2019. URL : http://journals.openedition.org/configuracoes/2077 ; DOI 10.4000/configuracoes.2077 


\title{
O pós-colonial entre Norte e Sul: formulações teóricas, implicações políticas na batalha pela 'arma da teoria'
}

\author{
Postcolonial between North and South: Theoretical formulations, political \\ implications in the battle for the "weapon of theory" \\ Postcolonialisme entre Nord et Sud: formulations théoriques, implications \\ politiques dans la bataille grâce à «l'arme de la théorie»
}

\section{Emanuelle Santos}

\begin{abstract}
debate, que apresentamos aqui a nossa opinião [...]. Àqueles que verão nela um carácter teórico, temos de lembrar que toda a prática fecunda uma teoria. E que, se é verdade que uma revolução pode falhar, mesmo que seja nutrida por teorias perfeitamente concebidas, ainda ninguém praticou vitoriosamente uma Revolução sem teoria revolucionária.

Amílcar Cabral
\end{abstract}

A recepção e o uso da chamada teoria pós-colonial como ferramenta para a análise das literaturas africanas em língua portuguesa é território complexamente controverso ${ }^{1}$. Se por um lado, a complexidade dessa controvérsia se dá por uma saudável e necessária atenção dada à significância do locus de produção da teoria, sempre alerta para continuações da lógica colonial no campo epistemológico, segundo as quais continua cabendo ao Norte explicar o Sul Global; por outro lado, é importante atentar para possíveis continuidades da lógica colonial inerentes à própria dialética entre as noções de centro e periferia quando evocada por uma crítica às literaturas africanas escritas em português, localizada principalmente em Portugal e no Brasil.

2 É com o intuito de embarcar no perigo dessas continuações, bem como na tentativa de lançar elementos que contribuam para o desenvolvimento dos debates acerca do pós- 
colonial na crítica literária de e em língua portuguesa, que toma forma esta breve intervenção. Num primeiro momento, traremos algumas questões acerca do pós-colonial como a "arma da teoria" em disputa na contenda epistemológica entre Norte e Sul para, a partir daí, endereçar continuidades e ruturas de um modelo de colonialidade do saber situado, protagonizado, ao mesmo tempo, a partir da zona limiar entre Norte e Sul, que constituem, num outro nível, o centro de gravidade de uma comunidade transnacional de língua oficial portuguesa.

\section{Na batalha pela "arma da teoria"}

3 No espaço transnacional de língua inglesa, hoje, a contenda acerca do pós-colonial ${ }^{2}$ evoluiu de uma contestação do tempo, expresso pelo nome-conceito, para uma discussão acerca da sua validade de operação na compreensão das relações do mundo na entrada do terceiro milênio ${ }^{3}$. Deslocando o foco do "quando?" para o "para quê?" pós-colonial, a discussão desenvolvida ao longo dos últimos vinte anos dentro desse espaço transnacional parece ter seguido um eixo linear, ao longo do qual, após o questionamento da formulação teórica centrada na análise do "pós", segue-se a problematização da sua relevância na medida em que o tempo histórico avança. Por outro lado, para grande parte da crítica literária de/em língua portuguesa, a contenda acerca do nome-conceito não foi resolvida; ela foi aprofundada, ao passo que se trouxe à tona a dimensão perpendicular do espaço à discussão acerca do tempo. 0 "onde?" juntou-se ao "quando?" no pós-colonial, e o "o quê?" interrompe sua caminhada em direção ao "para quê?", visto que o conceito adquire um valor político cuja problematização, necessária, é útil uma vez que o obriga a avançar.

4 No recente ensaio intitulado "'How to do things with concepts?': Articulações entre significantes políticos e begriffsgeschichte no pós-colonialismo situado" (2012), Roberto Vecchi envereda numa útil discussão acerca da significação política de conceitos que podemos aplicar ao valor político do qual é investido o pós-colonial na crítica em língua portuguesa. Embora a análise de Vecchi se faça num sentido diverso, ou seja, na tentativa de construir o "império" como um conceito de significância política, portanto performática, que busca delinear a especificidade do imperialismo português, sua informada construção acerca da significação política de conceitos, bem como da sua consequente relevância para as discussões epistemológicas, descreve, a meu ver, o processo através do qual o pós-colonial configura um problema para a crítica em língua portuguesa. Ao evocar a fecunda ideia de performatividade do discurso de John L. Austin em How to Do Things with Words, ideia essa aliada ao seu desenvolvimento histórico - ou "estrutura temporal interna" (Vecchi, 2012: 82) - e ao potencial político da performatividade tal como elaborada por Judith Butler, a proposta de Vecchi pode nos ajudar a compreender a estrutura a partir do qual o conceito de pós-colonial adquire sentido político na discussão da crítica em língua portuguesa.

5 A evocação da teoria pós-colonial para a crítica das literaturas africanas em língua portuguesa adquire sentido político na medida em que é vista como um ato enunciativo que se baseia na performance de um conceito teórico oriundo do Norte global. Compreendido desta forma, esse processo acarreta uma ambivalência epistemológica que em muito se assemelha àquela descrita por Bhabha (1990: 299), descortinando, assim, uma prática epistemológica (neo)colonial inerente ao uso do aparato teórico oferecido pelos estudos pós-coloniais. Por esta razão, o trabalho do crítico que se debruça sobre obras 
literárias tão comprometidas com o combate à logica colonial, em todas as suas formas e/ ou continuações, como são as obras concebidas nas literaturas africanas escritas em português, não poderia deixar de ser sensível à percepção dos menores indícios dessas mesmas continuações coloniais na ordem epistemológica.

Como o nosso detour, e consequente apropriação, pela reflexão de Vecchi pode mostrar, a estrutura para a significação política do pós-colonial enquanto prática epistemológica se apoia nos pilares da força enunciativa da performatividade do discurso e de uma tentativa de historicização do conceito expressa pela construção de genealogias. E enquanto na área de letras, principalmente no campo das literaturas africanas em português, a crença na força performativa do discurso ou da palavra como ato - ao que me recordo da formulação muito bem conseguida de Pires Laranjeira ao batizar seu Letra em Riste (1992) é quase incontestável por se colocar, muitas vezes, como ingrediente constituinte da estética literária, já no caso da historicidade do pós-colonial, que constitui justamente o aspecto principal pelo qual a crítica o condena, aquela mesma crença é mais contestável e menos uníssona do que um olhar apressado possa dar a entender.

Reinhart Koselleck, a quem Vecchi se refere como "nome dominante de referência" no campo da história conceitual de tradição alemã (Vecchi, 2012: 75), afirma que "[a]ny translation into one's own present implies a conceptual history, the methodological inevitability of which [...] [is shown] to be exemplary (paradigmatic) for all intellectual and social sciences" (Koselleck, 1989: 309). Deve ser por essa razão que quase toda menção ao que se chama "teoria pós-colonial" ou, de maneira mais compreensiva - embora não menos singular na sua designação bloco-monolítica -, "estudos pós-coloniais" é seguida por uma breve incursão, que se dedica a descrever "a" genealogia do campo.

8 Assim, deparamo-nos frequentemente, senão quase sempre, com descrições que se põem a destacar essa "uma teoria" ou esse "um campo" de forma bastante específica no seu locus e na sua orientação, ou seja, localizado na academia norte-americana e orientado pelo approach da trindade composta por Edward Said, Gayatri Spivak e Homi Bhabha.

9 É claro que a descrição do campo não é feita apenas da maneira simples e direta como a que acabo de resumir. "A" teoria/"o" campo é também, por vezes, inserida/o no território mais amplo do mundo anglófono - ou mais restrito do anglo-saxão -, e sua orientação teórica é por vezes localizada, não pela convocação de maitres à penser ilustrada na menção de nomes próprios, mas pela influência do pós-estruturalismo francês, nome-conceito já assombrado em si mesmo pela presença (toujours et déjà) espectral e controversa da filosofia de Jacques Derrida. Tais descrições de afã genealógico, entretanto, não se mostram erradas, mas incompletas. E sendo a incompletude inerente à própria história - quem dirá a incursões que parecem tentar remeter à ordem da história conceitual (ibid: : 310-311) -, tudo ficaria bem como está não fossem dois aspectos: o primeiro reside justamente na curiosa, quase unívoca, maneira através da qual o campo é descrito; e a segunda está na ordem dos efeitos da reiteração desse ato enunciativo - que adquire na repetição performativa, como vimos, valor político - na dialética centroperiferia/dentro-fora que a própria reiteração genealógica, feita da maneira como é feita, propõe e reitera.

10 Assim, se concordarmos com Boaventura de Sousa Santos, que abre as suas Epistemologias do Sul (2010) dizendo que "não há epistemologias neutras e as que reclamam sê-lo são as menos neutras" (2010: 7), e nos propusermos a desconstruir determinadas hegemonias epistemológicas, entendidas enquanto monopolizadoras do que se rotula como conhecimento válido, com vistas a uma prática que privilegie um diálogo de saberes - a 
que Santos chama "ecologia de saberes" -, será do interesse do crítico justamente afirmar aquilo que a epistemologia hegemônica deixa de fora, não? É verdade que o "póscolonial", enquanto rubrica acadêmica, teve espaço primeiro na academia angloamericana.

Mas, como sabemos, rubricas acadêmicas estão muito mais na ordem da justificativa para angariação de recursos e na organização do saber na forma de departamentos do que na ordem do pensamento propriamente dito. Mesmo Graham Huggan, no seu crítico Postcolonial Exotic (2001), não diminui a importância do pós-colonial como abordagem crítica apesar da intensa comodificação da qual é alvo ${ }^{4}$. Com isso em mente, parece muito mais estranho que a narrativa em língua portuguesa acerca do pós-colonial seja mais conectada ao florescimento de uma rubrica acadêmica do que à sua emergência histórica na onda descolonização/luta pela independência de possessões coloniais ocorrida após o final da Segunda Guerra Mundial, na qual a própria história colonial/africana em língua portuguesa participa - isso se não quisermos ser mais progressistas como Shohat e Stam que propõem uma interessante e compreensiva concepção do pós-colonial partindo dos "dois 1492" (Shohat e Stam, 2012a, 2012b, 2012c). Este pensamento esteve, inicialmente, profundamente calcado na problematização do encontro entre colonizador e colonizado na intenção de detectar e operar o desmontamento da lógica colonial, e compõe a substância do pensamento de importantes teóricos (não norte-americanos ou europeus) como Frantz Fanon, Aimé Cesaire, Edouard Glissant e Amílcar Cabral. Tal como afirma Robert Young - esse sim, devidamente anglófono, britânico, pós-estruturalista e com uma carreira que se estabelece entre Oxford e a Universidade de New York -, historicamente, a teoria pós-colonial é fruto de todas as formas de anticolonialismo, embora também escolha entre eles e seja muito mais conectada com o pensamento dos movimentos anticoloniais de cariz marxista de países da Ásia, América Central e, principalmente, África - incluindo justamente os cinco países africanos de língua oficial portuguesa (Young, 2003: 161).

12 Por outro lado, e aqui voltamos à proposição de Vecchi, a própria dimensão política do conceito pós-colonial, por ser, inevitavelmente, uma rubrica acadêmica cultivada primeiramente no Norte global e que tem como objeto de análise principal - ainda que não exclusivo ${ }^{5}$ - a vida no Sul global, acarreta inevitáveis odores de hierarquias coloniais e neocoloniais para os quais as narinas dos acadêmicos do Sul estão, com toda a razão que confere o exercício da experiência, alertas e sensíveis. Contudo, embora a negação do emprego de determinadas metodologias críticas, pela forma como se organizam (ou são organizadas) em torno de uma rubrica por fins políticos, seja uma posição absolutamente legítima, isso ainda é diferente de fazê-lo por uma deduzida incapacidade dessas perspectivas teóricas em função de sua "má" genealogia. Ademais, se a lógica vale, se provado que a indesejada "origem" descrita para esse conceito-como-método está errada por ser demasiadamente incompleta, seria de se esperar que corrigido o "erro" a rubrica então deixaria de ser um problema para a circulação das ideias que, disciplinarmente, concatena.

13 É interessante notar como o exercício de genealogizar o pós-colonial, conferindo-lhe uma narrativa com status de certidão de nascimento, funciona. No campo dos estudos literários em português, principalmente daqueles que enunciam a partir de Portugal e do Brasil, tal genealogização, com frequência, reclama alguma da autoridade conferida à história conceitual para justificar uma rejeição que é muito mais ligada à sua própria condição pós-colonial do que à dita problemática gênese dessa perspectiva crítica, 
rotulada como teoria. Assim, o incessante esforço de afirmar uma anglo-saxonidade ao pensamento pós-colonial pode refletir justamente o trauma da subalternidade que se converte na reificação de um excepcionalismo implícito à condição paradigmática de singularidade semiperiférica, garantindo o espaço necessário para a ereção de mitologias de exceção colonial com viés abrandador, tais como o luso-tropicalismo.

Por outro lado, se fosse realmente inspirado pela história conceitual, tal exercício genealogizador revelaria que, por ser extremamente recente e intrinsecamente conectado com a história do colonialismo e do imperialismo, o pós-colonial como conceito tem ainda uma definição bastante instável, seja pela própria instabilidade da conceptualização do império enquanto fenômeno histórico com o qual está intimamente relacionado, seja pela multiplicidade de experiências que o termo concatena já que não é apenas construído entre disciplinas, mas entre continentes, contando assim com compreensões culturalmente diferentes de cada um desses fenômenos - fato que também se deve ao alcance geográfico do império pelo braço armado do colonialismo. Isso nos leva a crer que uma comprometida tentativa de pensar o pós-colonial como conceito histórico, em vez de fechá-lo, termina por promover a sua abertura em termos de tempo e espaço, o que nos obrigaria a reconhecer sua pluralidade tanto de alcance como de elaborações, tal como Ella Shohat e Robert Stam mostram na forma como endereçam o problema (2012a: 380):

We would also take issue with genealogies for postcolonial theory that privilege national locations over transnational interlocutions. Dichotomous terms such as inside/outside, sender/receiver, and native/foreign draw overly bold lines between points of origin and points of reception within strongly demarcated national spaces. [Robert] Young's claim that "Postcolonial theory came from outside the U.S.," for example, implies that postcolonial theory travelled to the United States from some other place of origin, but in our view postcolonial theory emerged from a convulsion that impacted the entire world. Any strictly national framing provides only a very blunt instrument for reflecting on transnational intellectual flows. The seismic shift emerged in multiple locations, due to concrete historical conditions, notably the formation and dissolution of colonial empires and the overlays of multiply diasporized cultures existing in relations of subordination and domination within many nation-states, all combined with the emergence of institutional spaces where knowledgeable academics could articulate the issues.

$\mathrm{O}$ argumento de Shohat e Stam ganha ainda mais força quando recordamos que, no início dos anos 90, Ella Shohat foi uma das mais veementes vozes a contestar a funcionalidade e a pertinência da ideia do pós-colonial ${ }^{6}$. Sua crítica, necessária e importante como foi, não a impediu, entretanto, de reconhecer a operacionalidade do pensamento que corre sob a rubrica. Tal como ela afirma, vinte anos depois da sua mais pungente crítica: "[w]hile we certainly consider ourselves part of Postcolonial theory, we have also critiqued certain of its aspects" (2012c: 15). "I think the critique made in my essay ["Notes on the "Postcolonial'"] as well as in our Unthinking Eurocentrism still applies. But that does not mean that we should not use the term" (ibid.: 21). "I still believe we should use the term in a contingent manner" (ibid:: 23). Desmontado o mito do confinamento do pensamento póscolonial ao mundo anglófono como determinador da sua inoperância para uma reflexão acerca de artefatos culturais como os das literaturas africanas em língua portuguesa, o diálogo crítico com o corpo de formulações teóricas disponíveis o expande e potencializa, numa instrumentação crítica que é recíproca - e necessária - "it is all about the 'excess of seeing' (Bakthin), the complementarity of perspectives whereby we mutually correct and supplement each other's provincianisms" (ibid:: 23). 


\section{A centralidade da (semi)periferia}

16 A crítica às literaturas africanas aqui referida é, sem dúvida, aquela que enuncia a partir de Portugal e do Brasil. A importância desses loci de recepção crítica é claramente reconhecida, como afirma João Paulo Borges Coelho:

[n]o caso das literaturas africanas lusófonas, o locus da Crítica estrutura-se num eixo bipolar assente em Portugal (Lisboa, Porto, Coimbra) e no Brasil (São Paulo, Rio de Janeiro, Belo Horizonte) [...]. O eixo luso-brasileiro é poderoso, até porque os seus espaços institucionais de actuação são também os centros gravitacionais da língua portuguesa. Cria-se assim um contexto em que, por inércia, estão presentes vestígios da velha relação centro-periferia. (Coelho, 2012: 196-197)

17 A velha relação centro-periferia a que Borges Coelho se refere remete, no campo da literatura - embora saibamos que também fora dele -, às posições de Portugal e Brasil como centro, cabendo a Angola, Cabo Verde, Guiné-Bissau, Moçambique e São Tomé e Príncipe, ou seja, os cinco países africanos com literaturas em português, posições periféricas. Posições essas que se articulam em vários níveis, quais sejam, tanto a disputada posição de liderança de Portugal com relação ao Brasil na esfera do centro, quanto as hierarquias periféricas frente às quais as literaturas de Angola e Moçambique ocupam lugar de privilégio, a de Cabo Verde se vê em posição intermediária, fi cando as de Guiné-Bissau e São Tomé e Príncipe irremediavelmente à margem da margem. Frente a esse sistema, quase solar na sua arquitetura, não deixa de ser curioso que tenha emergido, justamente dos loci que ativamente buscam posições centrais, formulações teóricas dedicadas a explicar suas condições semiperiféricas.

Apesar do fato de a formulação teórica da condição semiperiférica de Portugal e periférica do Brasil ser do conhecimento geral no mundo das letras em língua portuguesa, sua menção se faz necessária se quisermos compreender algum dos efeitos que a rejeição do pós-colonial, pela sua percepção como uma formulação exclusivamente de um "outro" imperialista subjacente às referências à sua natureza anglófona, europeia ou mesmo anglo-americana, termina por acarretar. Antes de mais, acho pertinente recuperar uma importante reflexão com a qual Inocência Mata fecha seu artigo "A crítica literária africana e a crítica pós-colonial: um modismo ou uma exigência" (2007), na qual ela nos lembra que "tal, como o autor, o crítico é também um escritor - com todas as implicações que tem este estatuto em sociedades ainda precarizadas em termos técnico-culturais" (2007: 45). Se por um lado, Mata nos lembra de que, tal como no caso do autor, o trabalho do crítico também reflete um locus de enunciação (e esta condição o obrigaria à igual astúcia de não se deixar recolonizar por formulações teóricas ao sabor das modas, aderindo ao jargão do dia), por outro lado ela também nos lembra de, que tal como o escritor africano - ao exemplo dos sempre canônicos Luandino Vieira e Mia Couto -, o crítico pode/deve também apropriar e ab-rogar quaisquer formulações teóricas que lhe pareçam úteis, participando de forma ativa, crítica e criadora num espaço transnacional e alargado de conhecimento que constitui o pós-colonial. Afinal, se pensarmos em termos de sistemas-mundo, este crítico partilha, igualmente, da mesma modernidade que sustenta formulações críticas de outros lugares, ditos centrais ou não.

Isto posto, e concordando com Borges Coelho quando afirma que a crítica da qual falamos situa-se principalmente em Portugal e no Brasil, é possível perguntarmos até que ponto a escolha por uma não apropriação - e consequente ab-rogação - de determinadas 
formulações teóricas por parte dessa crítica não acontece também no intuito de afirmar sua centralidade ao cavar para si o lugar da exceção semiperiférica. Ao se autolocalizar do lado de fora de um modelo que julga exclusivamente euro-americano - passe o fato de que Portugal está na Europa e o Brasil está na América -, o crítico garante a si um espaço de excepcionalidade confi gurado a partir da inadequação tanto à categoria de centro, quanto à de periferia. De igual modo, contudo, ao mesmo tempo em que se distancia da categoria periférica por se localizar num espaço intermediário entre a periferia e o centro ao qual não relaciona outros pertencentes, termina por promover a "velha relação centro-periferia" perante a cultura da África de língua oficial portuguesa.

A este argumento corrobora, mais uma vez, o paralelismo entre autor e crítico. Uma vez que é comum que a crítica veja a influência do locus de enunciação no trabalho do autor, nada mais coerente que, compreendendo o crítico como escritor, investir na potencial influência das formas que organizam o pensamento no ambiente que o rodeia a si - e a seu público. Com isso em mente, é interessante observarmos a similaridade de um discurso de exceção de que se apropria muita da crítica oriunda de Portugal e do Brasil, o discurso da excepcionalidade.

21 No Brasil essa exceção toma, no campo da crítica literária, as formas bastante difundidas pelo ensaio-conceito "As ideias fora do lugar" ([1977] 2005) de Roberto Schwarz. Neste ensaio, o crítico opera uma importante e canônica análise socioeconômica da obra de Machado de Assis, na qual percebe "a disparidade entre a sociedade brasileira, escravista [do século XIX], e as ideias do liberalismo europeu" (Schwarz, 2005: 60). Nele o crítico segue no respeitável trabalho de analisar as especificidades da economia e da sociedade brasileira, mas, como falha em situá-las na sua conexão com o sistema de produção em escala mundial, acaba por produzir um pensamento do Brasil como exceção ${ }^{7}$, muito em sintonia com o projeto literário de formação de António Cândido que marcou profundamente o pensamento da crítica literária no Brasil ${ }^{8}$ - principalmente no campo da crítica das literaturas africanas em língua portuguesa -, característica de uma cultura que se pensa ainda, na dialética do dentro/fora, "nacional por subtração" (ibid.).

Já no caso de Portugal, o engendramento de uma especifi cidade (à la excepcionalidade) penetra a crítica através de uma formação muito mais contemporânea e, consequentemente, estruturada em termos de uma ampla dialética com o sistema de produção mundial. No já canônico "Entre Próspero e Caliban: colonialismo, póscolonialismo e inter-identidade" (2001), Boaventura de Sousa Santos faz dois movimentos importantes para a nossa discussão. Primeiramente, assim como coloca Portugal fora da teoria do colonialismo, visto que essa funciona em torno de um colonialismo hegemônico escrito em inglês (ibid.: 26-27), ele também localiza Portugal fora do escopo do pensamento pós-colonial, visto que, para o autor, "o pós-colonialismo é um fenômeno basicamente anglo-saxônico e toma como realidade fundadora o colonialismo britânico" ( ibid.: 30). Com isso, a proposta que é desenvolvida termina por ser a de não modificar os conceitos de colonial ou pós-colonial, no sentido de torná-los mais compreensivos e abertos para as várias e multifacetadas práticas coloniais e pós-coloniais inerentes às diferenças regionais inevitáveis dada a vastíssima área de alcance do binômio imperialismo/colonialismo. A proposta que se efetivou foi a da construção de uma teoria para um "pós-colonialismo português para designar o pós-colonialismo no espaço-tempo de língua oficial portuguesa" (ibid:: 40), que por mais que seja calcada no que o autor denomina como especifi cidade, termina por fomentar uma narrativa de excepcionalidade. 
É esta característica que põe em "estado de excepção" todo o discurso que se vire para as singularidades dos colonialismos e dos pós-colonialismos de Portugal. De facto a força - linguística, simbólica, citacional - da idealização de uma possível "civilização lusa", longe da norma dos outros colonialismos, reside no traço de ambiguidade declamatória que a plasma. (Vecchi, 2010a: 138) específicos de um sistema colonial e pós-colonial complexo e multifacetado como este, engendrado em português, é incontestavelmente importante para o corpo de teoria e crítica abarcada pela rubrica do pós-colonial. Se constituindo como arena acadêmica para a performance de diferenças, ao pós-colonial não cabe o prescritivismo, razão pela qual ele nada mais é do que uma perspectiva crítica que ganha corpo justamente através da adição de diferentes experiências de contato com o colonialismo através do globo. Assim, é evidente que do mesmo modo como as elaborações teóricas derivadas das análises de fenômenos específicos, tais como o pensamento luso-tropicalista ou o projeto cultural e político da lusofonia, são indispensavelmente úteis ao desenvolvimento do pensamento pós-colonial, porque não seria suplementarmente produtivo, por exemplo, pensar a literatura brasileira a partir da ideia de pós-colonialidade? Por que não usar as ferramentas desta perspectiva crítica como mais um recurso para compreender a (re)estruturação nacional dos Estados (europeus, africanos e americanos) na póscolonialidade?

Uma atitude produtivamente crítica, do ponto de vista epistemológico, no sentido de fomentar uma teoria pós-colonial adequada às especificidades das diversas e variadas realidades circunscritas às culturas que produzem em língua portuguesa é possível, não através de uma reconfiguração da relação centro-periferia, mas a partir do definitivo abandono dessa lógica. Nesse sentido, a proposta aqui consiste numa intervenção ativa ao nível teórico e analítico, diferindo de uma "indigenização dos estudos pós-coloniais" (Sanches, 2007: 129). Assim, a ideia de adaptação que ela implica não rompe com a lógica do dentro-fora que isola o (pós)colonialismo em língua portuguesa dos (pós)colonialismos em outras línguas europeias. Esse isolamento atribui à língua uma função de fronteira (Falconi, 2012: 204), não apenas separando, improdutivamente, diferentes instâncias de colonialismo, como também impedindo o desenvolvimento de outras perspectivas comparativas de cunho transnacional. 
27 A excepcionalidade (pós-)colonial encerrada no monolinguismo termina por promover “contiguidades ambíguas" ao nível teórico e crítico no que impede, por exemplo, que as literaturas africanas escritas em português sejam também compreendidas no quadro mais alargado das Literaturas Africanas Comparadas (Brugioni, 2012: 388).

28 Não é, portanto, através de uma recusa do pós-colonial pela sua base "anglófona" que se deve erguer um saber "lusófono". Tal como afirma Ana Paula Ferreira, "[t]o assume that this fi guration, no matter how refreshingly liberating it may sound, remains constant from Lisbon to Luanda, from Rio to Maputo is, however, to impose another version of the [neo]colonial privileged vision on supposedly postcolonial peoples, telling them what Portuguese can be or do for their always already sub-subaltern positions" (2007: 37).

A opção por uma construção epistemológica descentralizada e descentralizadora é, assim, possível através do engajamento e da apropriação do pós-colonial pelos quais é possível confrontá-lo, desautorizá-lo, corrigi-lo, reescrevê-lo. É a partir do contato, e não do distanciamento, com o outro que se pode, efetivamente, negociar as diferenças ao invés de hierarquizá-las, reificá-las. Dessa forma o pós-colonial enquanto prática epistemológica poderá, quiçá, passar a ser investido de outro valor largamente revolucionário, o valor político da inclusão.

\section{BIBLIOGRAPHY}

ADORNO, Theodor W. (2006), Indústria Cultural e Sociedade. São Paulo: Paz e Terra.

BHABHA, Homi (1990), Nation and Narration. Nova Iorque: Routledge.

BRUGIONI, Elena (2012), “Contiguidades ambíguas: Crítica pós-colonial e literaturas africanas”, in Leite, A. M.; Chaves, R. \& Apa, L. (orgs.) Nação e Narrativa Pós-Colonial. Lisboa: Edições Colibri, 379-394.

CABRAL, Amílcar (2008), Documentário. Lisboa: Edições Nova Cotovia.

COELHO, João Paulo Borges (2012), "Lugares da escrita, lugares da crítica”, in Brugioni, E.; Passos, J.; Sarabando, A. \& Silva, M.-M. (orgs.) Itinerâncias: Percursos e Representações da Pós-colonialidadel Journeys. Postcolonial Trajectories and Representations. Famalicão: Edições Húmus, 193-201.

FALCONI, Jessica (2012), “Literaturas Africanas, língua portuguesa e pós-colonialismos”, in Brugioni, E.; Passos, J.; Sarabando A. \& Silva, M.-M. (orgs.), Itinerâncias. Percursos e Representações da Pós-colonialidade / Journeys. Postcolonial Trajectories and Representations. Famalicão: Edições Húmus -CEHUM: 203-218.

FERREIRA, Ana Paula (2007), "Specifi city without exceptionalism: Towards a critical Lusophone potcoloniality”, in Medeiros, Paulo de (org.), Postcolonial Theory and Lusophone Literatures. Utrecht: Universiteit Utrecht, Portuguese Studies Centre, 21-40.

GILORY, Paul (2005), Postcolonial Melancholia. Nova Iorque: Columbia University Press.

HALL, Stuart (2003), “Quando foi o pós-colonial? Pensando no limite”, in Sovik, Liv (org.), trad.: Adelaine La Guardia Resende, Ana Carolina Escosteguy, Cláudia Álvares, Francisco Rüdiger e 
Sayonara Amaral: Da diáspora: Identidades e mediações culturais. Belo Horizonte: Editora UFMG, 101-130.

HUGGAN, Graham (2001), Postcolonial Exotic:Marketing the Margins. Londres e Nova Iorque: Routledge.

KOSELLECK, Reinhart (1989), "Social history and conceptual history”. Politics, Culture and Society 2:3, 308-325.

MATA, Inocência (2007), A Literatura Africana e a Crítica Pós-colonial: Reconversões. Luanda: Editorial Nizila.

MEDEIROS, Paulo de (2013), “7 Passos (para pensar uma Europa pós-imperial)”, in Leite, Ana Mafalda; Owen, Hilary, Chaves, Rita \& Apa, Livia (orgs.), Nação e Narrativa Pós-Colonial I: Angola e Moçambique. Lisboa: Edições Colibri, 323-338.

PARRY, Benita (2012), “What is left in postcolonial studies”, New Literary History 43:2, 341-358.

PARRY, Benita (2004), “The institutionalization of Postcolonial Studies”, in Lazarus, Neil (org.), The Cambridge Companion to Postcolonial Studies. Cambridge: Cambridge University Press, 66-82.

RICUPERO, Bernardo (2008), “Da formação à forma: Ainda as 'idéias fora do lugar'." Lua Nova 73: 59-69.

SANCHES, Manuela Ribeiro (2007), "Reading the Postcolonial: History, Anthropology, Literature and Art in a 'Lusophone Context"', in Medeiros, P. de (ed.) Postcolonial Theory and Lusophone literatures. Utrecht: Universiteit Utrecht, Portuguese Studies Centre, 29-148.

SANTOS, Boaventura de Sousa (2001), "Entre Próspero e Caliban: Colonialismo, pós-colonialismo e inter-identidades", in Ramalho, Maria Irene \& Ribeiro, António Sousa (orgs.), Entre Ser e Estar: Raízes, percursos e discursos da identidade. Porto: Edições Afrontamento, 23-86.

SANTOS, Boaventura de Sousa, \& MENESES, Maria Paula (2010), Epistemologias do Sul. Porto: Edições Afrontamento.

SANTOS, Emanuelle \& SCHOR, Patricia (2012), "Brazilian Postcolonialities.” P: Portuguese Cultural Studies 4.

SCHWARZ, Roberto (2005), “As idéias fora do lugar”, in Cultura e Política. São Paulo: Paz e Terra, 59-83.

SCHWARZ, Roberto (2005), “Nacional por subtração”, in Cultura e Política. São Paulo: Paz e Terra, 109-136.

SHOHAT, Ella (1992), "Notes on the 'Post-Colonial”, Social Text, n. 31/32, 99-113.

SHOHAT, Ella \& STAM, Robert (2012a), Race in Translation: Culture Wars around the Postcolonial Atlantic. Nova Iorque: New York University Press.

SHOHAT, Ella \& STAM, Robert (2012b), “'Brazil is not Travelling Enough': On Postcolonial theory and analogous counter-currents." P: Portuguese Cultural Studies, 15-40.

SHOHAT, Ella \& STAM, Robert (2012c), "Whence and whither postcolonial theory", New Literary History 43:2: 371-390.

VECCHI, Roberto (2010a), “O pós-colonialismo português: exepção vs. excepcionalidade?”, in Brugioni, E.; Passos, J.; Sarabando, A. \& Silva, M.-M. (orgs.), Áfricas Contemporâneas. Famalicão: Edições Húmus, 131-140.

VECCHI, Roberto (2010b), Excepção Atlântica: Pensar a Literatura da Guerra Colonial. Porto: Edições Afrontamento. 
VECCHI, Roberto (2012), “'How to do things with concepts?': articulações entre significantes políticos e begriffsgeschichte no pós-colonialismo situado”, in Brugioni, E.; Passos, J.; Sarabando, A. \& Silva, M.-M. (orgs.), Itinerâncias: Percursos e Representações da Pós-colonialidade. Famalicão: Edições Húmus, 75-85.

YOUNG, Robert J. C. (2012), “Postcolonial Remains”. New Literary History 43:1, 19-42.

YOUNG, Robert J. C. (2001), Postcolonialism: an Historical Introduction. Oxford: Blackwell Publishing.

\section{NOTES}

1. Entretanto a controvérsia quanto à produtividade da teoria não se restringe à crítica dessas literaturas, estendendo-se por todo o mundo de língua ofi cial portuguesa, ainda que fora do escopo deste ensaio. É interessante notar que a discussão se dá, em maior grau, no âmbito da literatura portuguesa, tal como informam os trabalhos de Santos $(2001,2010)$, Vecchi (2010b) e Medeiros (2013), e em menor grau nas discussões acerca da literatura brasileira, raramente endereçada nos termos do pós-colonial, como se vê em Santos e Schor (2012).

2. O "pós-colonial" de que falamos aqui refere-se a uma metodologia de leitura e análise de cultura que considera a relação dos objetos analisados com a ideologia colonial que parte do principio de que essa ideologia não acaba com o alcance das independências políticas. Esse modo de leitura também é chamado de "teoria pós-colonial”, “estudos póscoloniais" e "crítica pós-colonial", cada um dos três conectados entre si na medida em que são determinados por diferentes aspectos (teoria, estudos e crítica) inerentes ao póscolonial como modo de leitura.

3. Stuart Hall, no seu ensaio "Quando foi o pós-colonial? Pensando no limite" ([1996] 2003), resume muito bem a discussão acerca do termo "pós-colonial" tal como proposta por teóricos como Ella Shohat, Anne McClintock e Arif Dirlik no início dos anos 90. Para uma observação das problematizações atuais acerca do conceito, ver "Postcolonial remains" (2012) de Robert Young, bem como as respostas a este artigo escritas por Benita Parry, em "What is left in postcolonial studies?" (2012), e Ella Shohat e Robert Stam, em "Whence and whither postcolonial theory" (2012).

4. A comodificação do pós-colonial como rubrica acadêmica e "rótulo de venda no contexto do commodity cultural de hoje" (Haggam, 2001: ix) é uma crítica recorrente ao campo que nem sempre se dá de maneira construtiva. Constantemente evocada pela crítica marxista como fraqueza inerente ao método pós-estruturalista que subjaz a muito do que se produz a partir da perspectiva pós-colonial (Perry, 2004), a capitalização do pós-colonial pela indústria acadêmica e editorial, mais do que um problema exclusivo do campo, constitui um problema estrutural, inerente à lógica capitalista, que subjaz à indústria cultural como um todo (Adorno, 2006).

5. Ver, por exemplo, a dimensão pós-colonialidade europeia formulada em português nos trabalhos de Medeiros (2010) e Santos (2001) e em inglês nos trabalhos de Gilroy (2005).

6. Ver "Notes on the "Post-Colonial" de Ella Shohat (1992).

7. Sobre uma crítica ao pensamento de Schwarz, ver "Da formação à forma. Ainda as 'ideias fora do lugar"' (2008) de Bernardo Ricupero.

8. A relevância do pensamento de António Cândido para a crítica brasileira às literaturas africanas em língua portuguesa é tema de uma série de entrevistas feitas pela pesquisadora Anita Martins Rodrigues de Moraes publicadas nos números 7, 8, 9 e 12 da Revista Crioula, publicação online da Universidade de São Paulo. 


\section{ABSTRACTS}

No campo da crítica às literaturas africanas em língua portuguesa, a pertinência do pós-colonial como modo de leitura é contenciosa. No que se refere a uma crítica que enuncia a partir de espaços semiperiféricos como Portugal e Brasil, a suspeita em torno do pós-colonial é fundada numa experiência de subalternidade que, em termos globais, é inerente a uma vivência do Sul seja ele o Sul da América ou da Europa - que marca as relações de natureza centro-periferia que estabelece com o Norte. Experimentado como "uma teoria" ou "um campo acadêmico" predominantemente anglófono e oriundo do Norte Global, um engajamento com o pós-colonial a partir do Sul acarreta um posicionamento que é em si político, visto que combate aquilo que pode ser percebido como possíveis continuações, no campo epistemológico, de uma lógica colonial. Entretanto, em que medida o pós-colonial é, factualmente, uma perspectiva inerente exclusivamente ao Norte global? De que forma a ênfase num pós-colonialismo português, não reencena, no atual espaço transnacional de língua portuguesa, o mesmo tipo de relação centroperiferia que contesta na arena global? É a partir do levantamento desta e de outras questões que o presente trabalho aborda a contenda acerca da pertinência do pós-colonial para a análise das literaturas africanas em língua portuguesa.

In the field of critique of African literatures written in Portuguese, the relevance of the postcolonial as a mode of interpretation is a contentious issue. When it comes to a critique that proclaims from the semi/peripheral spaces of Portugal and Brazil, the suspicion regarding the postcolonial is based on an experience of subalternity which, in global terms, is inherent to an experience of the South - whether of South America or of Southern Europe - that marks the center-periphery relations it establishes with the North. When experienced as "a [predominantly Anglophone and Northern] theory" or "academic field" an engagement with the postcolonial from the South seems to entail a positioning that is in itself political. This is because it is a reaction to what can be perceived as possible continuations, in the epistemological field, of the colonial logic. Still, how far is the postcolonial actually a perspective solely inherent to the Global North? How does the emphasis on a Portuguese postcolonialism not re-enact in the current transnational space of Portuguese speakers the same center-periphery relation it contests in the global arena? It is by raising these and other questions that this paper gets to grips with the controversy about the relevance of the postcolonial to the analysis of African literatures written in Portuguese.

Dans le domaine de la critique des littératures africaines en langue portugaise, la pertinence du postcolonialisme comme moyen de lecture est controversée. En ce qui concerne une critique énoncée à partir d'espaces semi-périphériques tels que le Portugal et le Brésil, la suspicion autour du postcolonialisme est fondée sur une expérience de subalternité qui, en termes globaux, est inhérente à une expérience du Sud - que ce soit le Sud de l'Amérique ou le Sud de l'Europe qui marque les relations de nature centro-périphérique qu'il établit avec le Nord. Vécu comme «une théorie» ou «un domaine académique» principalement anglophone provenant du Nord Global, l'engagement avec le postcolonialisme à partir du Sud implique un positionnement qui est lui-même politique car il combat ce qui peut être perçu comme possibles continuations, dans le domaine épistémologique, de la logique coloniale. Toutefois, dans quelle mesure le 
postcolonialisme est-il vraiment une perspective inhérente exclusivement au Nord Global? De quelle manière l'idée d'un postcolonialisme portugais ne répète pas dans l'actuel espace transnational de la langue portugaise, le même type de relation centropériphérique qui est remis en question sur la scène mondiale? C'est à partir de l'enquête de cette question et d'autres que ce travail aborde le débat sur la pertinence du postcolonial dans l'analyse des littératures africaines en langue portugaise.

\section{INDEX}

Mots-clés: théorie postcoloniale, littératures africaines en langue portugaise, post-colonialisme portugais

Keywords: Postcolonial theory, African literatures in Portuguese, Portuguese postcolonialism Palavras-chave: Teoria pós-colonial, literaturas africanas em língua portuguesa, póscolonialismo português

\section{AUTHOR}

\section{EMANUELLE SANTOS}

University of Warwick

emanuelle.santos@warwick.ac.uk 